\title{
A NOTE ON THE RELATIONS OF CLASSES OF NUMERICAL SEQUENCES
}

\section{LÁSZLÓ LEINDLER}

Abstract. We investigate the interrelations of three classes of numerical sequences that have connection with the $L^{1}$-convergence of cosine series.

Mathematics subject classification (2010): 42A10, $26 \mathrm{D} 15$.

Keywords and phrases: Fourier coefficients, $L^{1}$-convergence.

\section{REFERENCES}

[1] G. A. Fomin, A class of trigonometric series, Mat. Zametki 23(1978), 213-222.

[2] L. LeIndLeR, On the equivalence of classes of Fourier coefficients, Math. Ineq. \& Applications 3(2000), 45-50.

[3] C. V. Stanojevič and V. B. Stanojevič, Generalizations of the Sidon-Telyakovskic theorem, Proc. Amer. Math. Soc. 110(1987), 679-684.

[4] S. A. TelYAKOVSKIǏ, On a sufficient condition of Sidon for integrability of trigonometric series, Mat. Zametki 14(1973), 317-328.

\section{SUPPLEMENTARY REFERENCES}

[5] J. NÉmeth, A note on two theorems of Leindler, Math. Ineq. Appl. 5(2), (2002), 225-233.

[6] Z. Tomovs KI, A note on some classes on Fourier coefficients, Math. Ineq. Appl. 2(1), (1999), 15-18.

[7] Z. Tomovs KI, Convergence and Inequality on some classes of trigonometric series, Dissertationes Mathematicae, 420(2003), 65 pp. 